\title{
Bariatrik Cerrahi Sonrası Bireylerin İştah Kontrolü ve Yeme Bağımlılıklarının Değerlendirilmesi
}

\author{
Assessment of Appetite Control and Food Craving Status of Individuals after Bariatric Surgery
}

\section{Selen Müftüoğlu1, Şevval Küçükağdaş²}

Geliş tarihi/Received: 08.07.2019 • Kabul tarihi/Accepted: 28.08.2019

\section{ÖZET}

Amaç: Bu çalışma, bariatrik cerrahi geçirmiş bireylerin iştah kontrolü ve yeme bağımlılıklarının değerlendirilmesi amacıyla planlanmıştır.

Bireyler ve Yöntem: Çalışmaya bariatrik cerrahi geçirmiş 400 birey dahil edilmiştir. Bireylerin sosyo-demografik özellikleri, beslenme alışkanlıkları, bariatrik cerrahi hakkındaki bilgi ve deneyimleri incelenmiştir. Bireylere 'Aşırı Besin İsteği Ölçeği' (ABİS) ve 'Duygusal İştah Anketi' (DİA) uygulanarak sonuçlar değerlendirilmiştir.

Bulgular: Yaş ortalaması 37.6 \pm 8.6 yıl olan 334 kadın (\%83.5) ve 66 erkek (\%16.5) birey çalışmaya katılmıştır. Kadın ve erkek katılımcıların beden kütle indeksi (BKİ) ortalamaları sırasıyla $28.6 \pm 5.9 \mathrm{~kg} / \mathrm{m}^{2}$ ve $29.6 \pm 6.1 \mathrm{~kg} / \mathrm{m}^{2}$ 'dir. Katılımcıların \%63.2'sinin daha sağlıklı olmak amacıyla vücut ağırlığı kaybettikleri belirlenmiştir. Katılımcıların \%87.8’inin Sleeve Gastrektomi yöntemi ile bariatrik cerrahi geçirdiği ve geçirilen bariatrik cerrahi ameliyatı üzerinden geçen sürenin ortalama $20.0 \pm 17.3$ ay olduğu belirlenmiştir. Cinsiyete göre bariatrik cerrahi öncesi zayıflama çayları/tozları/ilaçları kullanımı, hastalık durumları ve zayıflama isteğindeki amaçlar arasında istatistiksel açıdan anlamlı farklılıklar saptanmıştır ( $<<0.05)$. Katılımcıların vücut ağırlı̆̆ı değerleri ( $r=0.131, p=0.009)$ ve ana öğün sayıları ( $r=0.160, p=0.001)$ arttıkça DİA olumsuz toplam puan değerlerinin arttığı, fiziksel aktivite yaptıkları gün sayısı arttıkça DİA olumsuz toplam puan değerlerinin azaldığı saptanmıştır ( $\mathrm{r}=0.264$, $\mathrm{p}=0.000$ ). Ayrıca katılımcıların ABİS toplam puan değerleri arttıkça DİA olumsuz toplam puan değerlerinin de $\operatorname{arttığ~}$ belirlenmiştir $(r=0.448, \mathrm{p}=0.000)$.

Sonuç: Bariatrik cerrahi ve iştah kontrolü arasındaki ilişkinin belirlenebilmesi, bu hastaların iştah kontrollerini sağlayabilmeleri ve ileriki dönemde geri ağırlık kazanımının engellenmesi için oldukça önemlidir.

Anahtar kelimeler: Bariatrik cerrahi, iştah kontrolü, yeme bağımlılı̆̆

1. İletişim/Correspondence: Başkent Üniversitesi, Sağlık Bilimleri Fakültesi, Beslenme ve Diyetetik Bölümü, Ankara, Türkiye

E-posta: selenyilmaz@baskent.edu.tr • 『 https://orcid.org/0000-0001-6099-1182
2. Başkent Üniversitesi, Sağllk Bilimleri Fakültesi, Beslenme ve Diyetetik Bölümü, Ankara, Türkiye

ㄴ) https://orcid.org/0000-0001-8837-0943 


\section{ABSTRACT}

Aim: This study was planned to assess appetite control and food craving status of individuals who had bariatric surgery.

Subjects and Method: This study enrolled 400 individuals who had bariatric surgery. Socio-demographic characteristics, dietary habits, bariatric surgery knowledge and experiences of individuals were examined. Food Craving Questionnaire (FCQ) and Emotional Appetite Questionnaire (EMAQ) were used.

Results: 334 females (83.5\%) and 66 males (16.5\%) with a mean age of $37.6 \pm 8.6$ years participated in the study. The mean body mass index (BMI) of female and male participants was $28.6 \pm 5.9 \mathrm{~kg} / \mathrm{m}^{2}$ and $29.6 \pm 6.1 \mathrm{~kg} / \mathrm{m}^{2}$, respectively. Primary goal of weight loss was being healthy in $63.2 \%$ of participants. Sleeve Gastrectomy was the choice of bariatric surgery in $87.8 \%$ of the participants and mean post-operative duration was 20.0 17.3 months. According to gender, the frequency of using slimming teas/powders/medications before surgery, disease status and the aim of weight loss were significantly different between males and females $(p<0.05)$. EMAQ negative total score was positively associated with body weight $(r=0.131, p=0.009)$ and frequency of meal consumption $(\mathrm{r}=0.160, \mathrm{p}=0.001)$, however, it was negatively associated with physical activity performing days $(\mathrm{r}=0.264, \mathrm{p}=0.000)$. In addition, there was a positive correlation between total FCQ scores and EMAQ negative total scores $(r=0.448, p=0.000)$.

Conclusion: The understanding of the relationship between bariatric surgery and appetite control is important for these patients for the achievement of their appetite control and prevention of weight gain in the following years.

Keywords: Bariatric surgery, appetite control, food craving

\section{GíRiş}

Obezite, modern yaşam ile birlikte besin alımında meydana gelen artış ve fiziksel aktivitedeki azalış nedeniyle, özellikle gelişmiş ve gelişmekte olan ülkelerde görülme sıklığı hızla artan, en önemli sağlık ve beslenme sorunlarından biridir (1,2). Dünya Sağlık Örgütü (DSÖ) obeziteyi, "vücutta sağlığa zarar verebilecek anormal veya aşırı yağ birikmesi” olarak tanımlamaktadır (3). Obeziteyi tanımlama ölçütü olarak genellikle vücut ağırlığının (kg), boy uzunluğunun (m) karesine bölünmesiyle elde edilen "Beden Kütle İndeksi (BKİ)" kullanılır (2). Dünya Sağlık Örgütü, BKİye göre obeziteyi şu şekilde sinıflamaktadır: “24.99-29.99 $\mathrm{kg} / \mathrm{m}^{2}$ hafif şişman, $\geq 30.00 \mathrm{~kg} / \mathrm{m}^{2}$ obez, $30.00-34.99 \mathrm{~kg} / \mathrm{m}^{2} \mathrm{I}$. derecede obez, $34.99-39.99 \mathrm{~kg} / \mathrm{m}^{2}$ II. derecede obez ve $\geq 40.00 \mathrm{~kg} / \mathrm{m}^{2}$ morbid obez" (4).

Küresel Hastalık Yükü (Global Burden of Disease [GBD]) Obezite İşbirliği Grubu'nun 2015 yılı raporuna göre, dünyada obez nüfus 711.4 milyona (107.7 milyon çocuk ve 603.7 milyon yetişkin) ulaşmıştır $(5,6)$. İki bin on yılında 15 ildeki 540 merkezde gerçekleştirilen, 20 yaş ve üstü 26.499 kişinin katıldığı Türkiye
Diyabet, Hipertansiyon, Obezite ve Endokrinolojik Hastalıklar Prevalans Çalışması II (TURDEP II) obezite rakamları, Türkiye İstatistik Kurumu (TÜİK) 2016 yılı Adrese Dayalı Nüfus Kayıt Sistemi (ADNKS) yaş ve cinsiyet dağılımına göre standardize edildiğinde, ülkemizdeki 20 yaş ve üzeri yetişkinlerde obezite prevalansının \%29.5 (kadın \%35, erkek \%23.9) olduğu tahmin edilmekte, bu değerler obez birey sayısının ise 15.995.392'ye ulaşmış olduğunu göstermektedir $(5,7,8)$. Ekonomik İşbirliği ve Kalkınma Örgütü (Organisation for Economic Co-operation and Development [OECD])'nün 2017 raporunda ise, 2015 yılında 20-79 yaş yetişkinlerde 34 ülkenin ortalama obezite ve fazla kiloluluk prevalansı sirasıyla \%19.4 ve \%34.5 iken, Türkiye'de bu oranların sirasıyla \%22.3 ve $\% 33.1$ olduğu bildirilmiştir $(5,9)$.

Önlenebilir bir sağlık sorunu olan obezite, tıbbi beslenme (diyet), egzersiz, davranış değişikliği, farmakolojik (iştah baskılayıcılar) ve cerrahi yöntemler ile tedavi edilebilmektedir $(1,2)$. Bu yöntemler arasında tıbbi beslenme tedavisi anahtar rol oynasa da, özellikle morbid obez hastalarda tek 
başına yetersiz kalmaktadır (2). Aynı zamanda yapılan araştırmalarda cerrahi yöntem dişındaki tedavilerin genellikle uzun süreli vücut ağırlık kontrolünde etkisiz olduğu gösterilmiştir (10-16). Bu nedenle obez hastalarda diyet, egzersiz ve davranış değişikliğinin vazgeçilmez olduğu, gerekirse farmakolojik ve cerrahi yöntemlerin de uygulanabileceği ancak morbid obez hastalarda kalıcı başarı için cerrahi tedavinin etkili olabileceği düşünülmektedir (2).

Obezite cerrahisi endikasyonları ile ilgili ulusal ve uluslararası olmak üzere birçok rapor mevcuttur. Avrupa Klinik Uygulamalar Rehberi'ne göre diğer yöntemler ile kalıcı vücut ağırlığı kaybı sağlanamamış tüm hastalarda, BKİ $\geq 35 \mathrm{~kg} / \mathrm{m}^{2}$ olması durumunda komorbiditeler göz önüne alınarak cerrahi uygulama tavsiye edilmektedir (2,17). Türkiye Endokrinoloji ve Metabolizma Derneği (TEMD) Obezite Tanı ve Tedavi Kılavuzu'na göre: (1) $\mathrm{BKI} \geq 40 \mathrm{~kg} / \mathrm{m}^{2}$ olan bireylerde, cerrahi tedavi risk artışına neden olmuyorsa, obezite ilişkili bir komorbidite şartı aranmadan veya (2) BKİ $\geq 35 \mathrm{~kg} / \mathrm{m}^{2}$ olan ve obezite ile ilişkili tip 2 diyabet, hipertansiyon dislipidemi veya uyku-apne sendromu gibi en az bir komorbiditenin eşlik ettiği bireyler için cerrahi tedavi uygun görülmektedir (5). Bununla birlikte gebelik, ciddi gastrointestinal hastalıklar, aktif kanser, dekompanse kalp ve akciğer hastalığı, portal hipertansiyonun eşlik ettiği ileri karaciğer hastalığı, pulmoner hipertansiyonun eşlik ettiği kontrol altında olmayan uyku apne sendromu, ciddi hematolojik veya otoimmün hastalıklar bariatrik cerrahi açısından kontrendikasyon oluşturmaktadır. Yine aynı şekilde 18 yaş altı veya 65 yaş üzeri olmak da bariatrik cerrahi için rölatif kontrendikasyon olarak kabul edilmektedir (5).

Enerji alımını ve emilimi azaltmakiçin gastrointestinal sistemi değiştirme işlemleri olarak tanımlanan bariatrik cerrahi, kısıtlayıcı (restriktif), emilim bozucu (malabsorbtif) veya her ikisini kapsayan kombine yöntemleri içermektedir (18-20). Başvurulan başlıca bariatrik cerrahi yöntemleri Roux-En-Y Gastrik Bypass (RYGB), Laparoskopik Ayarlanabilir Gastrik Bant (LAGB), Sleeve Gastrektomi (SG) ve Biliopankreatik
Diversiyon (BPD)'dur (19). LAGB ve SG sadece kısıtlayıcı etki mekanizmasına sahipken, RYGB hem kısitlayıcı hem emilim bozucu etki mekanizmasına sahiptir. BPD tek başına kullanıldığında sadece emilim bozucu etki gösterirken, Duodenal Switch (DS) yöntemi ile beraber kullanıldığında hem emilim bozucu hem kısıtlayıcı etki göstermektedir $(19,20)$.

Bariatrik cerrahi sonrası hastaların beslenme şekli ve kalitesinde değişiklik meydana gelebilmektedir. Buna göre, ameliyatın ilk yılında hastaların \%48'inde özellikle hamurumsu makarna, pirinç, patates yemeği, ekmek ve ete karşı tolerans geliştiği ve beslenme ile ilgili kısıtlamalarda hayal kırıklığına uğramaları nedeniyle beslenme alışkanlıklarını değiştirmekte zorlandıkları belirtilmiştir (18,21). Ancak sekizinci yllın sonunda bu zorlukların \%42 oranında iyileştiği, az yemenin daha kolay hale geldiği, yeme sıklığını daha iyi kontrol ettikleri, daha iyi tokluk hissi oluştuğu ve tatlı tüketiminin azaltıldığı bildirilmiştir (18,21). Ameliyattan sonra enerji alımı ve iştah kontrolünün sağlanması konusunda bireylere destek olunması, sağlıklı yaşam için doğru beslenme alışkanlığı kazandırılması ve hastalara rehberlik edilmesi, hastaların beslenme kalitelerinin iyileştirilmesi için oldukça önemlidir (1).

Bariatrik cerrahi ve iştah kontrolü arasındaki ilişkinin belirlenebilmesi için öncelikli olarak iştah düzenleme mekanizması bilinmelidir. İştah düzenlemesinde ana yolak bağırsak-beyin aksıdır. Besin alımını kontrol eden hormonlar ikiye ayrılır. Bunlar, oreksijenik (iştah arttırıcı) ve anoreksijenik (iştah baskılayıcı) hormonlardır. Ghrelin, Nöropeptid Y (NPY), agouti-related protein (AGRP) oreksijenik hormonları oluştururken; leptin, kolesistokinin (CCK) ve glukagon benzeri peptid-1 (GLP-1) ise anoreksijenik hormonları oluşturur. Bariatrik cerrahi uygulamaları sonrası kısa dönemde leptin 3, 6 ve 12. haftalarda, CCK ise 10. haftada azalırken; ghrelin 6 . ayda artmaktadır. Artmış ghrelin ve azalmış leptin düzeyi açlık hissinin artışı ile ilişkilendirilir. İştah hormonlarının uyumsuzluğu ve buna bağll olarak gelişen şiddetli açlık ve yeme isteği ise bir ylla kadar 
uzayabilir (22). Ancak cerrahi müdahale geçiren hastaların pankreatik ve barsak peptid profillerindeki değişimlerin cerrahi müdahalenin türüne göre de farklılık gösterebileceği unutulmamalıdır (23). Burada önemli olan iştah kontrolü gibi kompleks bir sistemde fizyolojik mekanizmaların yanı sıra etkili olan diğer mekanizmalara (öğrenilmiş davranışlar/ alışkanlıklar, çevresel-sosyal faktörler, koku, görünüş, tat vb.) da önemle yaklaşılması ve özellikle hastaların psikolojik durumlarına da dikkat edilmesidir. Aksi takdirde hastada gerçekleşen çeşitli duygu durum bozuklukları, bu sürecin hasta tarafından yönetimini olumsuz etkilemektedir (23).

Tüm bu bilgiler ışığında bu çalışma, bariatrik cerrahi geçirmiş bireylerin beslenme alışkanlıkları, iştah kontrolü ve yeme bağımlılıklarının belirlenmesi amacıyla planlanıp yürütülmüştür.

\section{BIIREYLER VE YÖNTEM}

\section{Araştırmanın Yeri, Zamanı ve Örneklem Seçimi}

Bu araştırma, Ekim-Aralık 2018 tarihleri arasında bariatrik cerrahi geçirmiş, Türkiye'nin farklı şehirlerinden gönüllülük esası ile çalışmaya katılmayı kabul eden 20-70 yaş arası 400 birey ile yürütülmüştür. Örneklem seçiminde bariatrik cerrahi sonrası geçen süre (1-136 ay arası) dikkate alınmamıs ve dahil edilme kriteri olarak yalnızca bariatrik cerrrahi geçirme durumu belirlenmiştir. Bu çalışma Başkent Üniversitesi Tıp ve Sağlık Bilimleri Araştırma Kurulu tarafından 22.01.2019 tarihinde onaylanmış (Proje no:KA19/09) ve Helsinki Deklarasyonu Prensipleri'ne uygun bir şekilde yürütülmüştür.

\section{Araştırmanın Genel Planı}

Katılımclların sosyo-demografik özelliklerinin, beslenme alışkanlıklarının, bariatrik cerrahi bilgi birikimlerinin ve deneyimlerinin belirlenebilmesi için çoktan seçmeli ve/veya açık uçlu soruların bulunduğu bir anket formu uygulanmıştır. Anket formunda Aşırı Besin İsteği Ölçeği (ABİS)'ne ve Duygusal İştah Anketi (DİA)'ne de yer verilmiştir. Anket formu, online platformda katılımcılar tarafindan doldurulmuştur.

\section{Aşırı Besin İsteği Ölçeği [Food Cravings Questionnaire (ABİS)]}

Katılımcılara 9 faktör ve 39 maddeden oluşan ABİS ölçeği uygulanmıştır. Ölçekteki maddelerin tamamı 6'lı Likert tipindedir. Cepeda-Benito et al. (24) tarafından İngiltere'de geliştirilen bu ölçek, aşırı besin isteğinin objektif olarak ölçülebilmesi amacıyla kullanılmaktadır. Müftüoğlu ve arkadaşları (25) tarafından Türkçe geçerlilik-güvenirlilik çalışması yapılan ABİs ölçeğinin puan aralığı 39-234 arasında değişmektedir. Ölçekten alınan puan arttıkça, aşırı besin isteğinin de arttığı yorumu yapılmaktadır.

\section{Duygusal İştah Anketi [Emotional Appetite Questionnaire (DİA)]}

Katılımcılara 22 maddeden oluşan Duygusal İştah Anketi (DİA) uygulanmıştır. Anketteki maddelerin tamamı 9'lu Likert tipindedir. Nolan et al. (26) tarafındangeliştirilenbuölçek, duygusalyemekyemeyi değerlendirme amacıyla kullanılmaktadır. Demirel ve ark. (27) tarafından Türkçe geçerlilik-güvenirlilik çalışması yapılan DİA'nın puanlanmasında DİAolumsuz toplam puanı ve DİA-olumlu toplam puanı kullanılmaktadır ve hangi duygularda ve durumlarda özellikle duygusal yemek yemenin var olabileceği değerlendirilmektedir.

\section{Verilerin İstatistiksel Değerlendirmesi}

Çalışmadan elde edilen verilerin istatistiksel analizleri ve tabloların oluşturulması amacıyla SPSS (Statistical Package for Social Sciences) version 17.0 istatistik yazılım programı kullanılmıştır. Ölçümle elde edilen sürekli değişkenler ortalama $(\overline{\mathrm{X}})$ ve standart sapma (SS) ile sunulmuştur. Kategorik değişkenlerin sunumu için sıklık (S) ve yüzde (\%) değerler kullanılmıştır. Nicel değişkenlerin karşılaştırılmasında ilk olarak parametrik test koşullarının sağlanıp sağlanmadığı araştırılmıştır. Normal dağılım testlerinden en sık kullanilan Kolmogorov-Simirnov ve Shapiro-Wilks testleri kullanılmıştır. Değişkenler arasındaki ilişki iki 
yönlü korelasyon testi (normal dağılan parametreler için Pearson, normal dağllmayan parametreler için Spearman) ile araştırılmıştır. Bütün istatistiksel analizlerde önemlilik düzeyi $\mathrm{p}<0.05$ olarak kabul edilmiştir.

\section{BULGULAR}

Çalışmaya katılan katılımcıların sosyo-demografik özelliklerine ve sağlık durumlarına ilişkin verilerin dağılımı Tablo 1'de gösterilmiştir. Buna göre, çalışmaya katılan 400 kişinin \%83.5’i kadındır. Katılımcıların \%53.5'i üniversite mezunu ve \%50.2'si

Tablo 1. Katılımcıların sosyo-demografik özelliklerine ve sağlık durumlarına ilişkin verilerin dağılımı

\begin{tabular}{|c|c|c|}
\hline & $\mathbf{S}$ & $\%$ \\
\hline \multicolumn{3}{|l|}{ Cinsiyet } \\
\hline Kadın & 334 & 83.5 \\
\hline Erkek & 66 & 16.5 \\
\hline \multicolumn{3}{|l|}{ Eğitim Düzeyi } \\
\hline İlkokul & 17 & 4.3 \\
\hline Ortaokul & 22 & 5.5 \\
\hline Lise & 115 & 28.7 \\
\hline Üniversite & 214 & 53.5 \\
\hline Yüksek lisans & 25 & 6.3 \\
\hline Doktora & 7 & 1.7 \\
\hline \multicolumn{3}{|l|}{ Meslek } \\
\hline İşçi & 201 & 50.2 \\
\hline Ev hanımı & 83 & 20.8 \\
\hline Memur & 75 & 18.8 \\
\hline Emekli & 15 & 3.8 \\
\hline İşsiz & 14 & 3.4 \\
\hline Öğrenci & 12 & 3.0 \\
\hline \multicolumn{3}{|l|}{ Medeni Durum } \\
\hline Evli & 263 & 65.8 \\
\hline Bekar & 137 & 34.2 \\
\hline \multicolumn{3}{|l|}{ Hastalık Durumu } \\
\hline Evet & 147 & 36.8 \\
\hline Hayır & 253 & 63.2 \\
\hline \multicolumn{3}{|l|}{ Hastalık Türü } \\
\hline Diyabet & 43 & 19.8 \\
\hline Tiroid hastalıkları & 36 & 16.6 \\
\hline Hipertansiyon & 30 & 14.0 \\
\hline Kemik eklem hastalıkları & 30 & 14.0 \\
\hline
\end{tabular}

işçidir. Katılımcıların \%65.8'sinin evli olduğu tespit edilmiştir. Katılımcıların \%36.8'inde en az bir kronik hastalığın bulunduğu belirlenmiştir. En sık gözlemlenen hastalıklar diyabet (\%19.8), tiroid hastalıkları (\%16.6), hipertansiyon (\%14.0) ve kemikeklem hastalıkları (\%14.0)'dır (Tablo 1).

Tablo 2'de bireylerin antropometrik ölçümleri ve fiziksel aktivite düzeylerine ilişkin verilerin dağılımları verilmiştir. Kadın ve erkek katılımcıların ortalama vücut ağırlıkları sırasıyla $76.8 \pm 16.3 \mathrm{~kg}$ ve $94.2 \pm 19.7 \mathrm{~kg}$, ortalama boy uzunlukları sirasıyla $163.9 \pm 6.1 \mathrm{~cm}$ ve $178.3 \pm 6.4 \mathrm{~cm}$ ve ortalama BKİ sirasiyla $28.6 \pm 5.9 \mathrm{~kg} / \mathrm{m}^{2}$ ve $29.6 \pm 6.1 \mathrm{~kg} / \mathrm{m}^{2}$ 'dir. Kadınların \%33.2'sinin, erkeklerin ise \%43.9'unun hafif şişman olduğu tespit edilmiştir. Ayrıca kadınların \%31.1'inin BKİ açısından normal, erkeklerin ise \%22.7'sinin 1. derecede obez olduğu saptanmıştır.

Katılımcılar fiziksel aktivite yapma durumlarına göre incelendiğinde kadınların \%57.8'inin, erkeklerin ise \%60.6’sının fiziksel aktivite yaptığı belirlenmiştir (Tablo 2). Çalışmaya katılan kadınların \%63.3’ünün, erkeklerin ise \%56.4'ünün fiziksel aktivite türü olarak yürüyüş yaptığı tespit edilmiştir. Kadınların haftada ortalama $3.5 \pm 1.7$ gün ve günde ortalama $49.9 \pm 27.6$ dakika, erkeklerin ise haftada ortalama $4.0 \pm 1.6$ gün ve günde ortalama $63.1 \pm 31.1$ dakika fiziksel aktivite yaptıkları saptanmıştır (tabloda gösterilmemiştir).

Katılımcıların beslenme alışkanlıklarına ilişkin verilerin dağılımları Tablo 3’te gösterilmektedir. Buna göre katılımclların \%71.3'ünün 3 ana öğün, \%34.5’inin 3 ara öğün tükettiği tespit edilmiştir. Bariatrik cerrahi öncesi bireylerin \%24.5'i zayıflamak için bir ürün kullandıklarını belirtmiş ve ürün kullanan katılımcıların \%50.4'ünün zayıflama tozu kullandığı saptanmıştır. Zayıflama isteğinin amacı sorgulandığında, katılımcıların \%63.2'si “daha sağlıklı olmak” yanıtını vermiştir (Tablo 3).

Tablo 4'te bariatrik cerrahi türü ve bariatrik cerrahi hakkında bilgi alma yöntemine göre bireylerin dağılımları verilmiştir. Katılımcıların \%2.5'inde birden fazla cerrahi yöntem kullanılmıştır. 
Tablo 2. Katılımcıların antropometrik ölçümlerine ve fiziksel aktivite düzeylerine ilişkin verilerin dağılımı

\begin{tabular}{|c|c|c|c|c|}
\hline & \multicolumn{2}{|c|}{ Kadın (n=334) } & \multicolumn{2}{|c|}{ Erkek $(n=66)$} \\
\hline & $\overline{\mathrm{X}}$ & SS & $\overline{\mathrm{X}}$ & SS \\
\hline Vücut ağırlığı, kg & 76.8 & 16.3 & 94.2 & 19.7 \\
\hline Boy uzunluğu, cm & 163.9 & 6.1 & 178.3 & 6.4 \\
\hline \multirow[t]{2}{*}{ BKİ, kg/m² } & 28.6 & 5.9 & 29.6 & 6.1 \\
\hline & $\mathbf{S}$ & $\%$ & $\mathbf{S}$ & $\%$ \\
\hline \multicolumn{5}{|l|}{ BKİ sınıflaması (kg/m²) } \\
\hline$<18.5$ (zaylf) & 3 & 0.9 & 1 & 1.5 \\
\hline 18.5-24.9 (normal) & 104 & 31.1 & 12 & 18.2 \\
\hline 25-29.9 (hafif şişman) & 111 & 33.2 & 29 & 43.9 \\
\hline 30-34.9 (I. derecede obez) & 58 & 17.4 & 15 & 22.7 \\
\hline 35-39.9 (II. derecede obez) & 40 & 12.0 & 4 & 6.1 \\
\hline$\geq 40$ (morbid obez) & 18 & 5.4 & 5 & 7.6 \\
\hline \multicolumn{5}{|l|}{ Fiziksel aktivite yapma durumu } \\
\hline Evet & 193 & 57.8 & 40 & 60.6 \\
\hline Hayır & 141 & 42.2 & 26 & 39.4 \\
\hline \multicolumn{5}{|l|}{ Fiziksel aktivite türü* } \\
\hline Yürüyüş & 154 & 63.3 & 31 & 56.4 \\
\hline Yüzme & 17 & 7.0 & 8 & 14.5 \\
\hline Fitness & 35 & 14.4 & 11 & 20.0 \\
\hline Pilates & 23 & 9.5 & 1 & 1.8 \\
\hline Bisiklet sürme & 5 & 2.1 & 4 & 7.3 \\
\hline
\end{tabular}

*Çoklu cevap analizi ve \% değerleri fiziksel aktivite yapanlar üzerinden verilmiştir BKİ: Beden Kütle İndeksi

Katılımcılara en sık uygulanan cerrahi yöntem \%87.8 oranı ile SG'dir. Katılımcıların geçirdiği operasyonun üzerinden ortalama $20.0 \pm 17.3$ ay geçmiştir (tabloda gösterilmemiştir). Ayrıca bireylerin \%52.5'inin cerrahi hakkındaki bilgiyi sosyal çevrelerinden edindikleri saptanmıştır.

Tablo 5'te çalışmaya katılan katılımcıların ABİs, DİA olumsuz toplam ve DİA olumlu toplam puanlarma ilişkin verilerin dağılımları verilmiştir. Buna göre, kadın ve erkek katılımcıların ABİs puanları ortalamaları sirasiyla, $109.1 \pm 45.1, \quad 104.9 \pm 42.1$ 'dir. Cinsiyet ile ABİS puanı arasındaki ilişki istatistiksel açıdan anlamlı bulunmuştur $(p<0.05)$. Kadın ve erkek katılımcıların DİA olumsuz toplam puanları ortalamaları sirasıyla, $54.4 \pm 29.4, \quad 49.3 \pm 22.8$ 'dir. Cinsiyet ile DİA olumsuz toplam puanı arasındaki ilişki istatistiksel açıdan anlamlı bulunmamıştır ( $p>0.05)$. Kadın ve erkek katılımcıların DİA olumlu toplam puanları ortalamaları sirasıyla, 30.7 \pm 14.2 , $33.7 \pm 15.3$ 'dür. Cinsiyet ile DİA olumlu toplam puanı arasındaki ilişki istatistiksel açıdan anlamlı bulunmamıştır ( $p>0.05)$.

Tablo 6'da, DİA olumsuz toplam puanı ve BKİ ile çeşitli değişkenler arasındaki ilişkiler değerlendirilmiştir. Katılımcıların vücut ağırlığı arttıkça DİA olumsuz toplam puan değerlerinin de arttığı saptanmıştır $(\mathrm{r}=0.131, \quad \mathrm{p}<0.05)$. Katılımclların fiziksel aktivite sıklığı (gün/hafta) arttıkça DİA olumsuz toplam puan değerlerinin azaldığı belirlenmiştir ( $\mathrm{r}=-0.264$, $\mathrm{p}<0.05$ ). Katılımcların DİA olumsuz toplam puanı ile fiziksel aktivite süresi (dakika/gün) ve ara öğün sayısı arasındaki ilişkiler istatistiksel açıdan anlamlı bulunmamıştır ( $p>0.05)$. Katılımcıların ana öğün sayısı arttıkça DİA olumsuz toplam puan değerlerinin de arttığı belirlenmiştir ( $\mathrm{r}=0.160, \mathrm{p}<0.05)$. 
Tablo 3. Katılımcıların beslenme alışkanlıklarına ilişkin verilerin dağılımları

\begin{tabular}{lcc}
\hline & S & \% \\
\hline Ana öğün sayısı & & \\
1 & 8 & 2.0 \\
2 & 107 & 26.7 \\
3 & 285 & 71.3 \\
Ara öğün sayısı & & \\
$\quad 1$ & 47 & 11.8 \\
2 & 111 & 27.8 \\
3 & 138 & 34.5 \\
4 & 60 & 15.0 \\
5 & 23 & 5.7 \\
6 & 21 & 5.2 \\
Bariatrik cerrahi öncesi besin destek & & \\
ürünü kullanımı & & \\
Evet & 98 & 24.5 \\
Hayır & 302 & 75.5 \\
Bariatrik cerrahi öncesi kullanılan & & \\
ürün türleri* & & \\
Zayıflama çayları & 29 & 24.8 \\
Zayıflama tozları & 60 & 50.4 \\
Zayıflama ilaçları & 24.8 \\
Vücut ağırlığı kaybetme amacı & & \\
Daha sağlılı olmak & 253 & 63.2 \\
Daha iyi görünmek & 47 & 11.8 \\
Çocuk sahibi olabilmek & 5.2 \\
Daha rahat hareket edebilmek & 79 & 19.8 \\
*Çoklu cevap analizi ve\% değerleri ürün kullananlar üzerinden verilmiștir.
\end{tabular}

Tablo 6'da katılımcıların su tüketimi miktarları arttıkça DİA olumsuz toplam puan değerlerinin azaldığı saptanmıştır ( $\mathrm{r}=0.101, \mathrm{p}<0.05)$. Katılımcıların ABİS toplam puan değerleri arttıkça DİA olumsuz toplam puan değerlerinin de arttığı belirlenmiştir $(\mathrm{r}=0.448, \mathrm{p}<0.05)$. Katılımclların DİA olumlu toplam
Tablo 4. Katılımcıların geçirdikleri bariatrik cerrahinin müdahale türüne ve bariatrik cerrahinin öğrenilme metoduna ilişkin verilerin dağılımları

\begin{tabular}{lcc}
\hline & S & \% \\
\hline Bariatrik cerrahi türü & & \\
Sleeve gastrektomi & 361 & 87.8 \\
Roux-en-y gastrik bypass & 36 & 8.8 \\
Mini gastrik bypass & 8 & 2.0 \\
Laparoskopik ayarlanabilir gastrik bant & 4 & 1.0 \\
Biliopankreatik diversiyon & 1 & 0.2 \\
Duodenal switch & 1 & 0.2 \\
Bariatrik cerrahinin öğrenilme metodu & & \\
Sosyal çevre & 210 & 52.5 \\
Sosyal medya & 133 & 33.3 \\
Doktor & 53 & 13.2 \\
Diyetisyen & 4 & 1.0 \\
\hline
\end{tabular}

puan değerleri arttıkça DİA olumsuz toplam puan değerlerinin de arttığı bulunmuştur ( $r=0.468, p<0.05)$. Katılımclların BKİ değerleri arttıkça DİA olumsuz toplam puan değerlerinin de arttığı saptanmıştır $(r=0.166, p<0.05)$.

Tablo 6'da katılımcıların BKİ değerleri ile bir haftada fiziksel aktivite yaptıkları gün sayısı, haftada fiziksel aktivite yaptıkları dakika, ana öğün sayısı, ara öğün sayısı ve su tüketimi miktarı arasındaki ilişkiler istatistiksel açıdan anlamlı bulunmamıştır ( $p>0.05)$. Katılımcıların ABİS toplam puan değerleri arttıkça BKİ değerlerinin de arttığı belirlenmiştir ( $r=0.257$, $p<0.05)$. Katılımcıların DİA olumlu toplam puan değerleri arttıkça BKi değerlerinin de arttığı saptanmıştır $(r=0.154, \quad p<0.05)$. Katılımcıların bariatrik cerrahi süreleri ile DİA olumsuz toplam puan değerleri ve BKİ değerleri arasındaki ilişkiler istatistiksel açıdan anlamlı bulunmamıştır ( $p>0.05)$.

Tablo 5. Katılımcıların ABİS, DİA olumsuz toplam ve DİA olumlu toplam puanlarına ilişkin verilerin dağılımları

\begin{tabular}{lccccc}
\hline & \multicolumn{2}{c}{ Kadın (n=334) } & \multicolumn{2}{c}{ Erkek (n=66) } & p \\
\cline { 2 - 5 } & $\overline{\mathrm{X}}$ & SS & $\overline{\mathrm{X}}$ & $\mathbf{S S}$ & $0.036^{*}$ \\
Vücut ağırlı̆̆ı, kg & 109.1 & 45.1 & 104.9 & 42.1 & 0.668 \\
Boy uzunluğu, cm & 54.4 & 29.4 & 49.3 & 22.8 & 0.791 \\
BKİ, kg/m ${ }^{2}$ & 30.7 & 14.2 & 33.7 & 15.3 & 0 \\
\hline
\end{tabular}

${ }^{*} p<0.05$

ABİS: Aşırı Besin İsteği, DİA: Duygusal İştah Anketi 
Tablo 6. DİA olumsuz toplam puanı ve BKİ ile çeşitli değişkenler arasındaki ilişkilerin değerlendirilmesi

\begin{tabular}{|c|c|c|c|c|}
\hline & \multicolumn{2}{|c|}{ DİA olumsuz toplam puanı } & \multicolumn{2}{|c|}{ BKİ } \\
\hline & $\mathbf{r}$ & $\mathbf{p}$ & $\mathbf{r}$ & $\mathbf{p}$ \\
\hline Yaş (yıl) & 0.083 & 0.099 & 0.093 & 0.064 \\
\hline Vücut ağırlığı (kg) & 0.131 & $0.009^{*}$ & 0.892 & $0.000^{*}$ \\
\hline Boy uzunluğu (cm) & -0.038 & 0.445 & -0.041 & 0.416 \\
\hline Fiziksel aktivite sıklığı (gün/hafta) & -0.264 & $0.000^{*}$ & -0.002 & 0.974 \\
\hline Fiziksel aktivite süresi (dk/hafta) & -0.012 & 0.923 & -0.098 & 0.138 \\
\hline Ana öğün sayısı & 0.160 & $0.001^{*}$ & 0.065 & 0.193 \\
\hline Ara öğün sayısı & 0.094 & 0.061 & -0.024 & 0.629 \\
\hline Su tüketimi (mL/gün) & -0.101 & $0.044^{*}$ & -0.004 & 0.929 \\
\hline Bariatrik cerrahi süresi & 0.081 & 0.106 & -0.072 & 0.149 \\
\hline ABİS skor & 0.448 & $0.000^{*}$ & 0.257 & $0.000^{*}$ \\
\hline DİA skor & 0.468 & $0.000^{*}$ & 0.154 & $0.002^{*}$ \\
\hline BKİ $\left(\mathrm{kg} / \mathrm{m}^{2}\right)$ & 0.166 & $0.001^{*}$ & - & - \\
\hline
\end{tabular}

${ }^{*} p<0.05$

ABİS: Aşırı Besin İsteği, BKİ: Beden Kütle İndeksi, DİA: Duygusal Iş̧tah Anketi

\section{TARTIŞMA}

Bariatrik cerrahi geçirmiş bireylerin iştah kontrolü ve yeme bağımlılıklarının incelendiği bu araştırmada hem olumlu hem de olumsuz duygularla ilgili maddeleri içeren ve bireylerde yeme davranışlarının, duygularla ilişkisinin değerlendirilmesini sağlayan DİA ve aşırı besin isteğini tanımlamak ve ölçebilmek için geliştirilen ABİS Ölçeği kullanılmıştır. Araştırmanın sonuçlarına göre, katılımcıların DİA olumsuz toplam puanı ile fiziksel aktivite sıklığı (gün/ hafta) ve su tüketimi miktarları arasında negatif, vücut ağırlığı, ABİS toplam puanı, DİA olumlu toplam puanı, BKİ ve ana öğün sayısı arasında ise pozitif ilişki saptanmıştır $(p<0.05)$. Bireylerin özellikle olumsuz duygu ve durumlarda yeme isteğini kontrol etmede zorlandıkları ve bunun birçok parametre ile ilişkili olduğu belirlenmiştir.

$\mathrm{Bu}$ çalışmaya göre kadınların ABİs puanının, erkeklerin ABİS puanından fazla olduğu tespit edilmiş ve cinsiyet ile ABİS puanı arasındaki ilişki istatistiksel açıdan anlamlı bulunmuştur $(p<0.05)$. ABİS ölçek puanının artması aşırı besin isteğinde artışla ilişkili olduğundan, bariatrik cerrahi sonrası kadınların erkeklere kıyasla daha fazla besin isteği duydukları sonucuna ulaşılmıştır.
Guerdjikova et al.'un (28) bariatrik cerrahi geçirmiş 178 hasta üzerinde yapmış oldukları çalışmaya göre hastaların \%38.7'sinde duygusal yeme probleminin olduğu bildirilmiştir. Walfish tarafından (29) yapılan ve ameliyat öncesi duygusal durum ve yeme ilişkisinin değerlendirildiği bir başka çalışmada ise 122 kadın hasta değerlendirilmiş ve "sıkılmış, depresif, kaygılı, kızgin ve yorgun" hissetmenin obez kadın hastalarda duygusal yeme dönemlerine eşlik eden başlıca duygular olduğu ifade edilmiştir. Benzer şekilde bu araştırmada da bakılan parametrelerle (fiziksel aktivite sıklığı, su tüketimi miktarları, vücut ağırlığı, ABİS toplam puanı, BKİ) arasinda en fazla anlamlı ilişki bulunan verinin, olumsuz duygularla ilgili maddeleri içeren ve bireylerde yeme davranışlarının, duygularla ilişkisinin değerlendirilmesini sağlayan DİA olumsuz toplam puanı olduğu saptanmıştır.

Sonuç olarak, bariatrik cerrahi geçirmiş bireylerin iştah kontrolü ve yeme bağımlılıklarının değerlendirilmesi için planlanan ve yürütülen bu çalışma, cerrahi operasyon geçirmiş hastaların iştah kontrollerini sağlayabilmelerinde etkili olan bazı faktörleri ortaya koymuştur. Çalışmada kullanılan ölçeklerin kesme noktaları olmadığından 
katılımcıların iştah durumları ile ilgili net sonuçlar verilememekte ancak ölçekten aldıkları puanlar arttıkça yeme isteklerinin arttığı söylenebilmektedir. İştah kontrolü özellikle ileriki dönemlerde geri vücut ağırlığı kazanımının engellenmesi için oldukça önemlidir. $\mathrm{Bu}$ hasta grubunun, cerrahiye ilişkin komplikasyonlarla baş edebilmelerinin yanı sıra yaşam boyu sürecek diyet, egzersiz ve yaşam tarzı değişikliğine uyum sağlayabilmeleri için doğru bir iştah kontrolü sağlamaları ve bu konuda yetkin sağlık profesyonellerinden yardım almaları oldukça önemlidir.

$\mathrm{Bu}$ araştırmanın en önemli kısıtlllığı, uygulanan ölçeklerin yalnızca bariatrik cerrahi sonrası uygulanmasıdır. Bundan dolayı elde edilen veriler bariatrik cerrahi öncesi ile karşılaştırılamadığ için aradaki farklılıklar da kesin olarak belirlenememektedir. Bu bağlamda yapılacak olan araştırmaların hem bariatrik cerrahi öncesi hem de bariatrik cerrahi sonrası uygulanarak karşılaştırılması bilimsel açıdan daha etkili olacaktır. Aynı zamanda yeme davranışını etkileyebilecek olası risk faktörleri göz önünde bulundurularak yapılması gereken daha detaylı analizlerin yapılmaması, çalışmanın diğer bir sinırlılığıdır. Bu nedenle, daha detaylı analizlerin yapıldığı, daha büyük örneklem sayısına sahip çalışmaların yapılması gerekmektedir.

Çıkar çatışması - Conflict of interest: Yazarlar çıkar çatışması olmadığını beyan ederler. - The authors declare that they have no conflict of interest.

\section{KAYNAKLAR}

1. Çelik E, Karabulut E, Bilgiç P. Bariatrik cerrahi hastalarında beslenme ve davranıs tutumu ölçeği. J Nutr Diet. 2017;45(2):107-15.

2. Yüksel A. Bariatrik cerrahi operasyonu geçiren morbid obez bir hastanin 3 yll sonraki beslenme durumu: olgu sunumu. İzmir Katip Çelebi Üniversitesi Sağlık Bilimleri Fakültesi Dergisi. 2016;1(1):39-45.

3. World Health Organization. Obesity and overweight. February 16, 2018. Available at: http://www.who.int/ news-room/fact-sheets/detail/obesity-and-overweight Accessed June 13, 2019.
4. World Health Organization. Obesity: Preventing and Managing the Global Epidemic: Report of a WHO Consultation on Obesity. Geneva, Switzerland: World Health Organization; 2000. 252 p. Report No.:894.

5. Türk Endokrinoloji ve Metabolizma Derneği (2019). Obezite Tanı ve Tedavi Kılavuzu. Erişim: http://temd.org. tr/admin/uploads/tbl_kilavuz/20190506163904-2019tbl_ kilavuz5ccdcb9e5d.pdf Erişim Tarihi: 13 Haziran 2019.

6. Global Burden of Disease [GBD] 2015 Obesity Collaborators, Afshin A, Forouzanfar MH, Reitsma MB, Sur P, Estep K, et al. Health effects of overweight and obesity in 195 countries over 25 years. N Engl J Med. 2017;377(1):13-27.

7. Satman İ, Ömer B, Tütüncü Y, Kalaca S, Gedik S, Dinççağ $\mathrm{N}$, et al. Twelve-year trends in the prevalence and risk factors of diabetes and prediabetes in Turkish adults. Eur J Epidemiol. 2013;28(2):169-80.

8. Türkiye İstatistik Kurumu Başkanlığı [TÜİK] Adrese Dayalı Nüfus Kayıt Sistemi (2016). Erişim: http://ingev. org/wp-content/uploads/2017/02/n\%C3\%BCfus-vevatanda\%C5\%9Fl\%C4\%B1k-verileri-t\%C3\%BCik.pdf Erişim Tarihi: 13.06.2019.

9. Organisation for Economic Co-operation and Development [OECD] Health Statistics (2017). Health at a Glance. Available at: http://.dx.doi. org/10.1787/888933602956 Accessed June 13, 2019.

10. Avenell A, Broom JI, Brown TJ, Poobalan A, Aucott LS, Stearns SC, et al. Systematic review of the long-term effects and economic consequences of treatments for obesity and implications for health improvement. Health Technol Assess. 2004;8(21):1-182.

11. Chang SH, Stoll CR, Song J, Varela JE, Eagon CJ, Colditz GA. The effectiveness and risks of bariatric surgery: an updated systematic review and meta-analysis, 20032012. JAMA Surg. 2014;149(3):275-87.

12. Chang SH, Stoll CR, Colditz, GA. Cost-effectiveness of bariatric surgery: should it be universally available? Maturitas. 2011;69(3): 230-8.

13. Chauhan V, Vaid M, Gupta M, Kalanuria A, Parashar A. Metabolic, renal, and nutritional consequences of bariatric surgery: implications for the clinician. South Med J. 2010;103(8):775-83.

14. Lara MD, KothariSN, Sugerman HJ. Surgical management of obesity: a review of the evidence relating to the health benefits and risks. Treat Endocrinol. 2005;4(1):55-64.

15. McTigue KM, Harris R, Hemphill B, Lux L, Sutton S, Bunton AJ, et al. Screening and interventions for obesity in adults: summary of the evidence for the US Preventive Services Task Force. Ann Inter Med. 2003;139(11):93349.

16. Ochner CN, Gibson C, Carnell S, Dambkowski C, Geliebter 
A. The neurohormonal regulation of energy intake in relation to bariatric surgery for obesity. Physiol Behav. 2010;100(5):549-59.

17. Tsigos C, Hainer V, Basdevant A, Finer N, Fried M, Mathus-Vliegen E, et al. Management of obesity in adults: European clinical practice guidelines. Obes Facts. 2008;1(2):106-16.

18. Yurdakul C. Bariatrik Cerrahi Sonrası Hastaların Beslenme Kalitelerinin Uzun Dönemde Klinik ve Antropometrik Ölçümlere Etkisi [Bilim Uzmanlığı Tezi]. İstanbul Medipol Üniversitesi Sağlık Bilimleri Enstitüsü, İstanbul; 2015.

19. Öner C. Bariatrik Cerrahi Hastalarında Tat Alma ve Besin Tüketimindeki Değişikliklerinin Vücut Ağırlığına Etkisi [Bilim Uzmanlığı Tezi]. İstanbul Medipol Üniversitesi Sağllk Bilimleri Enstitüsü, İstanbul; 2015.

20. Sağlam F, Güven H. Obezitenin cerrahi tedavisi. Okmeydanı Tıp Dergisi. 2014;30:60-5.

21. Erdem NZ, Kahraman F. Bariatrik hastaların diyetlerinin izlenmesi. Merdol Kutluay T, editör. Temel Beslenme ve Diyetetik. Birinci baskı. Ankara: Güneş Tıp Kitabevleri; 2015. s. 355-82.

22. Yavuz Y. Bariatrik cerrahilerin gastrointestinal hormonlar üzerine etkisi. Turkiye Klinikleri J Gen SurgSpecial Topics. 2012;5(2):31-7.

23. Müftüoğlu S. İştah Kontrolü ve Geri Ağırlık Kazanımının
Engellenmesi. Bariatrik Cerrahi ve Beslenme Sempozyumu, 24-25 Mart, 2018, Ankara, Türkiye. Sempozyum kitabı 2018; s. 110-7.

24. Cepeda-Benito A, Gleaves DH, Williams TL, Erath SA. The development and validation of the state and trait foodcravings questionnaires. Behav Ther. 2000;31(1):151-73.

25. Müftüoğlu S, Kızıltan G, Ok MA. Majör depresyon hastaları için "Aşırı Besin İsteği” ölçeğinin Türk kültürüne uyarlanması: geçerlilik ve güvenirlilik çalışması. Turkiye Klinikleri J Health Sci. 2017;2(1):1322.

26. Nolan LJ, Halperin LB, Geliebter A. Emotional Appetite questionnaire. Construct validity and relationship with BMI. Appetite. 2010;54(2):314-9.

27. Demirel B, Yavuz KF, Karadere ME, Şafak Y, Türkçapar MH. Duygusal İştah Anketi'nin Türkçe geçerlik ve güvenilirliği, beden kitle indeksi ve duygusal şemalarla ilişkisi. Bilişsel Davranışçı Psikoterapi ve Araştırmalar Dergisi. 2014;3:171-81.

28. Guerdjikova AI, West-Smith L, McElroy SL, Sonnanstine T, Stanford K, Keck PE. Emotional eating and emotional eating alternatives in subjects undergoing bariatric surgery. Obes Surg. 2007;17(8):1091-6.

29. Walfish S. Self-assessed emotional factors contributing to increased weight gain in pre-surgical bariatric patients. Obes Surg. 2004;14(10):1402-5. 